\title{
PReS-FINAL-2271: Assessment of
} musculoskeletal abnormalities in children with mucopolysaccharidoses using a simple musculoskeletal examination (paediatric gait, arms, legs and spine)

\author{
MO Chan ${ }^{1 *}$, ES Sen ${ }^{2}$, E Hardy ${ }^{2}$, T Rapley ${ }^{3}$, P Hensman ${ }^{4}$, E Wraith ${ }^{4}$, H Foster $^{5}$ \\ From 20th Pediatric Rheumatology European Society (PReS) Congress \\ Ljubljana, Slovenia. 25-29 September 2013
}

\section{Introduction}

Mucopolysaccharidoses (MPS) are rare inherited disorders with a spectrum of phenotypes resulting from glycosaminoglycans (GAGs) accumulation in cells. Children with MPS often have musculoskeletal (MSK) abnormalities ranging from joint contractures to deforming abnormalities of the extremities and spine. pGALS (paediatric Gait, Arms, Legs, and Spine), is a simple MSK assessment which has been previously validated in school-age children to detect abnormal joints.

\section{Objectives}

Our aim was to describe the use of pGALS to identify patterns of MSK abnormalities in children with MPS.

\section{Methods}

Videos of children with a spectrum of MPS performing pGALS were made at an MPS specialist centre as part of their routine care and independent of the current study. Informed consent for the use of the videos for research was obtained. A piloted proforma to record abnormalities for each pGALS manoeuvre observed in the videos (scored as normal/abnormal/not assessable) was used by 3 observers (2 paediatric rheumatology (PRh) trainees and 1 specialist PRh physiotherapist and all blinded to MPS subtype). Videos were scored independently by the 3 observers and videos re-scored for

${ }^{1}$ Paediatric Rheumatology, University of British Columbia, Vancouver, Canada Full list of author information is available at the end of the article intra- and inter-observer consistency. Data were pooled and analysed.

\section{Results}

15 videos of children ( 9 boys, 6 girls, median age 11 years [4-19]) with MPS (10 MPS type I Hurler-Scheie (HS); 4 MPS type II; 1 mannosidosis) were assessed. The most common abnormalities detected using pGALS exam were restriction of shoulder, elbow, wrist, temporomandibular joint excursion (likely impacted by many children having enlarged digits) $[>75 \%$ cases] and spinal deformity/restriction ( $2 / 3$ cases). Mean intra-observer Kappa 0.74 (range 0.65-0.88) and inter-observer Kappa 0.62 (range 0.51-0.77). Hip manoeuvres within pGALS were not clearly demonstrated in the videos.

\section{Conclusion}

In this observational study, pGALS identifies MSK abnormalities in children with MPS. Restricted joint movement (and especially upper limb) was a consistent finding. We acknowledge that further work is needed to include pGALS assessment of the hip and also to test pGALS in an additional population of children with MPS; notably in further children with MPS I-HS as this subtype often has MSK abnormalities as the only feature. The use of pGALS and awareness of patterns of joint involvement may be a useful adjunct to facilitate earlier recognition of these rare conditions and facilitate access to specialist care. 


\section{Disclosure of interest}

None declared.

\section{Authors' details}

${ }^{1}$ Paediatric Rheumatology, University of British Columbia, Vancouver, Canada.

${ }^{2}$ Paediatric Rheumatology, Great North Children's Hospital, Newcastle upon

Tyne, UK. ${ }^{3}$ Institute of Health and Society, Newcastle University, Newcastle

upon Tyne, UK. ${ }^{4}$ Manchester Children's Hospital, Manchester, UK.

${ }^{5}$ Musculoskeletal Research Group, Institute of Cellular Medicine, Newcastle

University, Newcastle upon Tyne, UK.

Published: 5 December 2013

doi:10.1186/1546-0096-11-S2-P261

Cite this article as: Chan et al:: PReS-FINAL-2271: Assessment of musculoskeletal abnormalities in children with mucopolysaccharidoses using a simple musculoskeletal examination (paediatric gait, arms, legs and spine). Pediatric Rheumatology 2013 11(Suppl 2):P261.

Submit your next manuscript to BioMed Central and take full advantage of:

- Convenient online submission

- Thorough peer review

- No space constraints or color figure charges

- Immediate publication on acceptance

- Inclusion in PubMed, CAS, Scopus and Google Scholar

- Research which is freely available for redistribution

Submit your manuscript at www.biomedcentral.com/submit
Ciomed Central 